\title{
Representações Sociais do Crack na Mídia
}

\author{
Daniel Rohe Salomon da Rosa Rodrigues ${ }^{1}$ \\ Maria Inês Gandolfo Conceição \\ Ana Luísa da Silva Iunes \\ Universidade de Brasilia
}

\begin{abstract}
RESUMO - O crack tem sido tema recorrente em matérias jornalísticas e discursos políticos. O objetivo do estudo foi identificar como a mídia local representa a droga. Baseadas na Teoria das Representações Sociais foram analisadas 76 reportagens de 2009 do jornal Correio Braziliense, utilizando-se o software ALCESTE que gerou seis classes. Destacaram-se três representações sociais: droga como flagelo da humanidade, ações policiais indistintas contra usuários ou traficantes e internação do usuário como solução do problema. As representações sociais encontradas alinham-se com a abordagem estigmatizante e repressiva ao usuário de drogas que ainda o considera ora como criminoso, ora como doente e perpetuam sua clandestinidade e limitam a compreensão do fenômeno.
\end{abstract}

Palavras-chave: representação social, crack, ALCESTE, mídia

\section{Social Representation of Crack Cocaine in Brasilia's Media Press}

\begin{abstract}
Crack cocaine has been a recurrent topic in newspaper articles and in recent political speeches. This research aimed to identify how the local media represents the drug. Based on the Theory of Social Representations 76 articles published during 2009 in the Correio Braziliense newspaper were analyzed. The content of the articles was analyzed with the software ALCESTE, which generated six classes. Three social representations were highlighted: drug as a scourge of humanity, indistinct police actions against users and drug dealers and hospitalization as a solution of the problem. We observed that the social representations are consistent with a stigmatizing and repressive approach, which still consider drug users as criminal or sick persons, reinforcing the maintenance of their underground status and limiting the understanding of the phenomenon.
\end{abstract}

Keywords: social representation, crack cocaine, ALCESTE, media

O crack tem desafiado os profissionais e o sistema público de saúde, configurando-se atualmente em um dos principais alvos das políticas de governo (Brasil, 2010). É objeto de interesse acadêmico na realização de pesquisas, e.g., acerca de seus efeitos nos pulmões (Mançano et al., 2008), sua relação com HIV/AIDS (Carvalho \& Seibel, 2009), seus padrões de uso (Oliveira \& Nappo, 2008), as causas de morte de seus usuários (Duailibi, Ribeiro, \& Laranjeira, 2006), além de investigações envolvendo produções de sentido acerca do crack nas mídias (Chagas \& Seeger, 2013; Romanini \& Roso, 2012).

No Brasil, o consumo de crack alastrou-se principalmente entre crianças, adolescentes e adultos que vivem na rua, o que gerou pressões por parte de diversos atores sociais que impulsionaram ações visando a garantir oportunidades de vida mais digna e saudável a essa população, historicamente desassistida (Duailibi et al., 2008). Esse grupo social é acometido por problemas como o desemprego, a falta de acesso à saúde, educação e habitação, que se consubstanciam como fatores fortemente relacionados ao uso de crack (Guimarães, Santos, Freitas, \& Araújo, 2008).

Pesquisas vêm apontando que a droga é utilizada predominantemente por homens entre 25 e 34 anos,

1 Endereço para correspondência: SQN 402, Bloco S, Apto 105, Brasília, DF, Brasil. CEP: 70834-190. E-mail: rohe.daniel.1986@gmail.com desempregados, com baixa escolaridade, com baixo poder aquisitivo, provenientes de "famílias desestruturadas", sendo também consumida por meninos em situação de rua e usuários de drogas injetáveis (Guimarães et al., 2008). Contudo é possível notar que, nos últimos anos, o usuário de crack também se tornou presente em classes econômicas mais privilegiadas (Duailibi et al., 2008).

Segundo o último levantamento epidemiológico sobre usuários de crack e drogas similares (cocaína e merla), realizado pela FIOCRUZ (Bastos \& Bertoni, 2013), 370 mil pessoas são usuárias de crack no Brasil e mais da metade desses usuários faz uso diário da droga. Nas capitais federais, os usuários fumam em média 16 pedras por dia.

O VI Levantamento Nacional sobre o Consumo de Drogas Psicotrópicas entre Estudantes do Ensino Fundamental e Médio nas 26 Capitais Brasileiras e Distrito Federal (CEBRID, 2012) aponta que o uso do crack entre alunos de escolas públicas é maior, em termos do percentual de alunos dessa rede, do que nas escolas particulares. A faixa etária de estudantes com mais de 19 anos compreende o grupo com maior porcentagem de usuários. Os estudantes do sexo masculino superam, em percentual de usuários, o sexo feminino.

Um dos fenômenos associado ao uso de crack é o craving (ou fissura), que é o desejo súbito e intenso de usar determinada substância, podendo ocorrer na fase de consumo, no início da abstinência ou após um longo período 
sem consumir a droga, normalmente acompanhado de alterações no humor, no comportamento e no pensamento. O manejo do craving é uma ferramenta importante para evitar a recaída, para o qual a literatura recomenda ouso da técnica do relaxamento respiratório para minimizá-lo, uma vez que em estado de relaxamento, a probabilidade de agir impulsivamente é menor (Zeni \& Araújo, 2009).

Embora o crack deixe o sujeito em euforia plena, esse estado rapidamente desaparece, sendo seguido por depressão. Para sair do estado depressivo e sentir novamente euforia, o usuário consome uma nova dose. Para obtê-la para consumo, o usuário acaba se envolvendo em atividades ilegais, tais como roubo, furto e violência, ou em práticas como a troca de sexo por crack. Entre outros efeitos da droga podemos listar a insônia, comportamento violento, tremores, paranoia, problemas no sistema respiratório, cansaço intenso, forte depressão e desinteresse sexual. O uso continuado da droga pode causar ataque cardíaco, derrame cerebral, contrações no peito seguidas de convulsões e coma, além de poder levar a déficits neuropsicológicos significativos e ao desenvolvimento de outras doenças graves como infarto, derrame e doenças reumáticas (Cunha, Nicastri, Gomes, Moino, \& Peluso, 2004).

Frequentemente, o usuário de crack é poliusuário de drogas ou possui antecedente de consumo de outras substâncias (Cierco, 2003). A presença de um segundo diagnóstico é comum entre os usuários de cocaína e crack. As comorbidades psiquiátricas mais relatadas em estudos brasileiros são depressão e transtornos de ansiedade. Observa-se que o índice de abandono de tratamento é alto entre esses usuários, o que torna a multiplicidade de propostas de atendimento necessária para garantir maior adesão ao tratamento (Silva, Kolling, Carvalho, Cunha, \& Kristensen, 2009).

Além das consequências fisiológicas, o dependente de crack sofre de graves problemas de ordem psicossocial que se refletem no modo como o usuário de drogas ilícitas em geral tem sido visto e tratado. Em se tratando de pessoas em situação de vulnerabilidade social, a questão psicossocial é agravada pelo processo de dupla exclusão social (Sudbrack, 2010): o usuário de crack, morador de rua, é marginalizado por sua condição de extrema pobreza e é criminalizado por ser usuário de droga. Historicamente o usuário de drogas ilícitas tem recebido tratamentos contraditórios, sendo tratado ora como doente, ora como criminoso. Tanto uma como outra forma de tratamento levam à estigmatização e contribuem para mantê-lo na clandestinidade, limitando a compreensão do fenômeno. Por isso, as abordagens exclusivamente repressivas que acompanham essa visão têm se mostrado insuficientes e ineficazes, tendo grande responsabilidade na reprodução da violência associada ao mundo das drogas (Santoucy, Conceição, \& Sudbrack, 2010).

Dessa forma, tem sido recorrente associar o uso do crack à violência. Usualmente, as propostas de soluções convergem na direção de intervenções psiquiátricas e jurídicas, contrariando o que preconiza a política de atenção ao usuário de álcool e outras drogas vigente no país (Brasil, 2005). As drogas deveriam ser vistas enquanto fenômeno complexo que envolve questões psicológicas, econômicas, sociológicas e políticas (Romanini \& Roso, 2012).
Nessa esteira, a nova Política Nacional sobre Drogas (Brasil, 2005) propôs uma mudança de paradigma na abordagem aos usuários ou dependentes de drogas. Prevêse, por um lado, para o traficante, penas duras de prisão, enquanto que, os usuários ou dependentes recebem medidas alternativas e, por vezes, são encaminhados para tratamento médico gratuito não compulsório. A nova lei sobre drogas Lei 11.343/2006, que institui o Sistema Nacional de Políticas Públicas sobre Drogas em seu Art. $1^{\circ}$ (Brasil, 2006), não prevê a legalização do uso de drogas. No entanto, o porte de drogas para consumo pessoal perdeu seu caráter de "crime", mas continua sendo uma infração para a qual cabe a aplicação de outras sanções, de forma que o usuário já não pode ser chamado de "criminoso".

A perspectiva da nova lei é a da redução de danos, acrescida de uma série de implicações práticas. A diferença essencial diz respeito à pena: a nova lei não mais prevê a prisão para usuários, que são enquadrados no seu Art. 28. A lei de drogas prevê para aqueles que usam substâncias ilícitas as seguintes sanções: a) admoestação verbal; b) prestação de serviços à comunidade; c) medida educativa de comparecimento a programa ou curso educativo (Brasil, 2006).

Assim como as suas antecessoras, a nova lei parte da ideia de prevenir a sociedade em relação ao mal-estar provocado pelos problemas sociais advindos do consumo de drogas. Entretanto, o olhar que a lei destina ao usuário transita entre a patologização e a criminalização - pois ainda se fala em penas, que carregam o conteúdo semântico de castigo, punição (Santoucy et al., 2010).

Estudos recentes apontam que o imaginário sobre o crack que circula na mídia envolve a ideia de que a droga é como um ente com vida própria que tem por objetivo destruir as famílias; que ela deve ser combatida com todos os esforços, ainda que os estudos na área das ciências da saúde não ratifiquem essas posições (Chagas \& Seeger, 2013; Romanini \& Roso, 2012). Considerando-se o sistema de difusão midiático como produto de um diálogo social, ele configura-se, portanto, como ambiente de circulação de representações sociais (Moscovici, 1978) e veículo de divulgação das mesmas (Camargo \& Barbará, 2004).

As representações sociais referem-se a um fenômeno típico da sociedade moderna e são categorias de pensamento que expressam, explicam, justificam e questionam a realidade (Moscovici, 2003). Para Jodelet (1986) e Moscovici (1978), as representações sociais são formas de conhecimento do mundo que são construídas a partir do agrupamento de conjuntos de significados que permitem dar sentido a fatos novos ou desconhecidos.

Moscovici e Vignaux (1994) postulam que toda representação social corresponde à expressão reiterada nos discursos e nas trocas de teses entre grupos ou categorias de indivíduos de interesses opostos, nas quais eles negociam themata. Os themata são antinomias oriundas do senso comum que assumem importância maior no meio social e atraem a atenção da opinião pública. Muitas são as formas de pensar do senso comum, mas nem todas se tornam themata, apenas aquelas mais relevantes (Valsiner, 2012). Assim, a criação de representações sociais dá-se no encontro de pessoas dispostas a falar, argumentar e discutir o cotidiano, 
por meio de uma relação dialética que oscila entre a tensão e a integração de teses opostas (Moscovici \& Vignaux, 1994).

Jovchelovitch (1995) introduz a importância de compreender o conceito de alteridade para entender como as representações sociais se estabelecem. Ela afirma que o ser humano possui as capacidades de fala e ação, e através dessas capacidades estabelece comunicação. Por sua vez, as comunicações em massa - produto e produtora da modernidade - trabalham no sentido de reforçar atitudes e pensamentos já formados e estabelecidos na sociedade. A troca de informação quotidiana é mediada pelos canais de comunicação sob a forma de símbolos e representações. A realidade social é constituída pelas representações que estão no sujeito. A soma das construções particulares resulta em uma totalidade maior que se desafia, se reproduz, se repete e se supera, formando a vida social de uma comunidade. São as mediações sociais que geram as representações sociais tanto em sua constituição, como em sua forma de ser (Rouquette, 1984/1988).

De acordo com Cierco (2003), ocorre uma mediação por parte da mídia entre as pessoas e os fatos reais. São criados assim os "pacotes de realidade" nos quais os indivíduos não vivem diretamente, nem interagem com os fatos da realidade quotidiana em si se não por meio desses "pacotes". Assim, se não há, por parte do receptor da informação, uma capacidade em controlar a precisão da representação social, o sujeito acaba por absorver uma imagem distorcida, estereotipada ou manipulada. Dessa forma, o conhecimento que nós temos dos fatos que acontecem para além do nosso meio social imediato é, muitas vezes, captado das formas simbólicas veiculadas pelos meios de comunicação (Thompson, 2007).

Um grande número de pesquisas tem sugerido que as notícias da mídia contribuem para as agendas públicas, retóricas oficiais, políticas e formação do senso comum sobre os problemas sociais, assim como para direcionar a preferência da opinião pública por certas soluções (Altheide, 2000; Altheide \& Michalowski, 1999). Pesquisas baseadas na análise de matérias de jornais acerca da abordagem dada ao tema das drogas revelam que a mídia apresenta informações sensacionalistas. Além disso, ela dissemina o pânico moral e divulga informações sem fundamentação científica e podem pressionar as autoridades a investir em outros problemas sociais (Cierco, 2003; Romanini \& Roso, 2012).

O potencial de imbricamento entre os meios de comunicação em massa, o senso comum e o imaginário social nos leva, frente às recentes discussões lançadas na mídia sobre o crack, a investigar como a questão vem sido abordada. É preciso identificar as contradições que existem no pensamento da sociedade a respeito do crack, de forma a verificar quais são os componentes dos themata acerca da droga que acabam por se agrupar em determinadas representações sociais.

É fundamental, portanto, compreender o conteúdo veiculado nos meios de comunicação de massa sobre o uso do crack e outras drogas para buscar as representações sociais. Esse processo nos ajuda a entender como a sociedade e a mídia acompanham as mudanças acerca da legislação sobre o uso de drogas, partindo de uma hipótese de que continua havendo criminalização de usuários de drogas ilícitas, mesmo após a vigência da Lei 11.343 (Veríssimo, 2010).
Este estudo pretende explicitar o modo como a mídia aborda o tema e averiguar como ela dialoga com a nova legislação e coma política nacional sobre drogas, haja vista o caráter formador de opinião que os meios de comunicação possuem. Portanto, este trabalho tem como objetivo, por meio do estudo das representações sociais e da identificação de themata, analisar e problematizar a maneira como um jornal impresso de grande circulação local se pronuncia frente ao problema atual do crack em Brasília/DF e em seu entorno.

\section{Método}

A pesquisa teve como base empírica as matérias publicadas no ano de 2009 no jornal de maior circulação de Brasília/DF e Entorno: o Correio Braziliense. O período foi escolhido por ter sido o ano que antecedeu a criação do plano de enfrentamento ao crack e ainda porque, nesse ano, foi observado um grande número de notícias nos meios de comunicação de massa sobre "a invasão do crack" nas cidades brasileiras. Essa constatação foi feita no trabalho vencedor do prêmio nacional de monografias promovido pela Secretaria Nacional de Políticas sobre Drogas do Ministério da Justiça, no ano de 2010.

Primeiramente, foram localizadas no sitio eletrônico do jornal as reportagens que continham a palavra "crack" no período de janeiro a dezembro de 2009. Como critério de inclusão na pesquisa, foram escolhidas apenas matérias que tratassem do "crack" enquanto droga, excluindo-se as matérias que continham o termo crack com outro conteúdo semântico. Dessa forma, foram selecionadas 76 reportagens.

A análise das matérias selecionadas foi realizada por meio do software ALCESTE (Analyse Lexicale par Contexte d'un Ensemble de Segment de Texte), que consiste em uma ferramenta produtora de indicadores de representação social (Lima, 2008). Ele permite a identificação de categorias do discurso, propiciando a análise comparativa dos temas encontrados. O ALCESTE recorre à análise das ocorrências e das co-ocorrências das palavras nos enunciados que constituem o texto, para organizar e sumarizar informações consideradas mais relevantes segundo o critério de quiquadrado $\left(\chi^{2}\right)$. A regularidade de um vocabulário específico indica a existência de um "campo contextual" com um espaço semântico específico (Nascimento \& Menandro, 2006).

A metodologia ALCESTE passa por quatro etapas em seu processo de análise. Na primeira etapa, o programa realiza uma leitura do corpus discursivo distribuídos em Unidades de Contexto Inicial $\left(\mathrm{UCI}^{1}\right)$ e faz um cálculo dos dicionários. $\mathrm{Na}$ segunda etapa são selecionadas as frequências das palavras em sua forma reduzida e são definidas as Unidades de Contexto Elementar (UCE ${ }^{2}$ ), que são matrizes do discurso que constituem a base para a análise do texto. É também na segunda etapa que o programa gera a classificação hierárquica descendente (CHD), que nos permite a identificação da associação dos themata encontrados neste estudo.

1 As UCI são formadas a partir da combinação inicial de partes do texto distribuídas entre as variáveis escolhidas para o estudo.

2 As UCE são criadas pela análise ALCESTE e, constituem-se em segmentos de texto que são incorporadas às classes geradas pelo software. 
A terceira etapa consiste na comparação entre os dados obtidos nas primeiras duas etapas, sendo que somente os dados estáveis são considerados para os perfis de cada classe. Nessa etapa é feita a análise fatorial de correspondência (AFC) referente ao cruzamento entre as formas reduzidas e as classes formadas. Por fim, a quarta etapa destina-se aos cálculos complementares e à criação de listas de formas reduzidas de cada classe, além de definir qual UCE pertencerá a cada classe.

Após o procedimento de análise e síntese, o software gera um relatório que permite a investigação dos resultados por parte dos pesquisadores. Nele identificamos as formas reduzidas de maior relevância segundo o critério de quiquadrado, assim como fizemos a leitura das UCE de cada uma das classes do estudo, levantando a ideia principal contida nelas e expondo-a no formato de um pequeno resumo, que nos auxilia a identificar o conteúdo semântico encerrado no mundo lexical daquela classe. Cada um dos seis mundos lexicais distintos foi utilizado para definir o título que demos a cada uma das classes.

Foi também realizada a análise dos gráficos descritores das articulações semânticas entre as classes. Um deles, da CHD, permite observar a frequência de UCE nas classes. O outro, da AFC, exige lembrar, para sua correta compreensão, quanto mais distantes estiverem os elementos dispostos no gráfico, mais distantes são os significados dos seus léxicos. A partir da leitura da CHD e da AFC é possível observar algumas antinomias no corpus textual por meio da leitura da disposição das classes e da sua relação com os eixos 1 e 2 , respectivamente.

Após a identificação dos themata, as antinomias em evidência na mídia, e das suas inter-relações baseadas nas oposições entre as classes conforme a CHD e a AFC, levantamos aquelas que compunham as representações sociais identificadas nesse estudo. Elas foram elaboradas com base nos dados obtidos mediante uma abordagem pragmática da linguagem baseada no agenciamento operacional dos conceitos de themata de Moscovici e Vignaux (1994) e dos fundos tópicos de Reinert (citado por Lima, 2008), que operam no nível do imaginário coletivo e da linguagem, respectivamente. A equivalência semântica entre themata e fundos tópicos se dá em virtude da oposição entre ideias que os dois conceitos trazem e porque são ligados à produção de sentido a partir do encadeamento de lexemas (Lima, 2008).

Uma vez detectado no discurso da mídia um posicionamento antinômico oriundo do senso comum, temos um thema que posteriormente pode ser entendido, de maneira contínua e flexível, como uma representação social. O ALCESTE nos auxilia na determinação dos diferentes pontos de vista onde se articulam o mundo e a linguagem. De posse desse recurso, é preciso que o pesquisador obtenha informações a respeito dos elementos que dinamizam as relações inter-grupo, de como essas relações determinam o uso do léxico e o fluxo da comunicação e, finalmente, identificar os themata que fomentam a construção das representações contidas nos mundos lexicais (Lima, 2008).

As matérias jornalísticas foram inseridas no corpus discursivo do estudo e distribuídas de acordo com o dia de cada edição do jornal (cada dia recebeu um grupo de variáveis). Assim, cada matéria recebeu uma variável referente ao mês e outra referente ao caderno do jornal (Opinião, Cidade, Brasil e Ciência), no qual a matéria daquela edição estava. Assim, as 76 reportagens foram transformadas em 93 UCI, já que numa edição do Correio, poderia haver uma matéria em mais de um dos cadernos do jornal. Os termos compostos foram modificados de forma que aparecessem juntos (por exemplo, o termo delegacia de polícia apareceu no corpus assumindo a forma delegacia_de_policia).

\section{Resultados}

A base empírica constituída por 76 reportagens e 41.593 palavras gerou 856 UCE. Na Figura 1 podemos verificar a existência de seis classes, sendo que a classe lagrupou 194

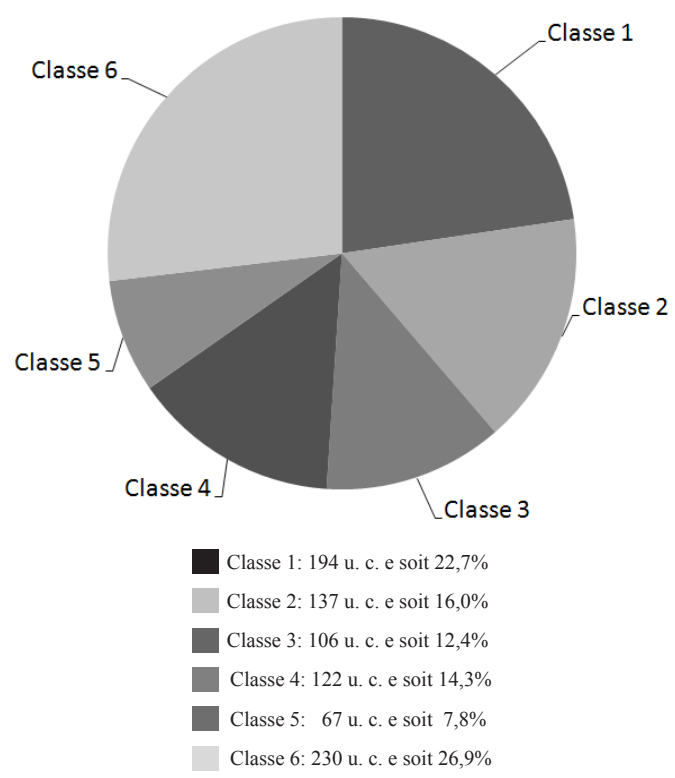

Figura 1. Distribuição das Unidades de Contexto Elementar nas classes 
UCE, representando 22,7\% do corpus; na classe 2 foram 137 UCE ou $16 \%$ do total; na classe 3 encontramos 106 UCE em $12,4 \%$ do corpus; na classe 4 estão 122 UCE e 14,3\% do corpus; na classe 5 contam-se $67 \mathrm{UCE}$ indicando 7,8\% do corpus e; na classe 6 foram alocadas $230 \mathrm{UCE}$, representando $26,9 \%$ do corpus.

Os mundos lexicais presentes em cada uma das classes desse estudo estão representados na Tabela 1 que lista as presenças de formas reduzidas mais relevante em cada classe, de acordo com o critério de $\chi^{2}$ : violência. Foram descritas a "perda da esperança de uma vida melhor", assim como a dor da perda de parentes por mortes violentas e assassinatos associados ao uso da droga, além de outras violências intrafamiliares. Nessa classe, pode-se perceber uma relação entre droga e dinheiro como motivadora das situações de violência.

Classe 2 - A cena de tráfico e consumo (maconha e crack). Essa classe é marcada pela denúncia que o jornal faz sobre o uso de drogas ilegais em determinadas áreas da cidade de Brasília/DF, evidenciando que o consumo agora ocorre de forma dispersa nos espaços públicos e não mais circunscrito a determinado espaço privado, como ocorria

Tabela 1. Lista das principais formas reduzidas das classes 1 a 6 e respectivos valores de $\chi^{2}$

\begin{tabular}{|c|c|c|c|c|c|}
\hline Classe & & & Formas Reduzidas & & \\
\hline Cl. 1 & $-\operatorname{mae}\left(\chi^{2}=106\right)$ & - filh $\left(\chi^{2}=90\right)$ & $-\operatorname{mor}\left(\chi^{2}=74\right)$ & - pai $\left(\chi^{2}=54\right)$ & $-\operatorname{cas}\left(\chi^{2}=48\right)$ \\
\hline Cl. 2 & - quadr $\left(\chi^{2}=140\right)$ & - residenci $\left(\chi^{2}=111\right)$ & - bloco $\left(\chi^{2}=102\right)$ & $-\operatorname{norte}\left(\chi^{2}=95\right)$ & $-\operatorname{comerci}\left(\chi^{2}=82\right)$ \\
\hline Cl. 3 & - policia $\left(\chi^{2}=140\right)$ & - pres $\left(\chi^{2}=93\right)$ & - quadrilha $\left(\chi^{2}=78\right)$ & $-\operatorname{acusad}\left(\chi^{2}=63\right)$ & $\begin{array}{l}\text { - delegacia_de_policia } \\
\left(\chi^{2}=56\right)\end{array}$ \\
\hline Cl. 4 & - apreens $\left(\chi^{2}=97\right)$ & $-\operatorname{coca}\left(\chi^{2}=66\right)$ & $-\operatorname{merla}\left(\chi^{2}=54\right)$ & $-\operatorname{crack}\left(\chi^{2}=53\right)$ & - aument $\left(\chi^{2}=53\right)$ \\
\hline Cl. 5 & - explor $\left(\chi^{2}=119\right)$ & - boate $\left(\chi^{2}=83\right)$ & $-\operatorname{rodovia}\left(\chi^{2}=83\right)$ & $-\operatorname{sexual}\left(\chi^{2}=73\right)$ & $-\operatorname{esmol}\left(\chi^{2}=71\right)$ \\
\hline Cl. 6 & - saude $\left(\chi^{2}=95\right)$ & - $\operatorname{psiquiatr}\left(\chi^{2}=74\right)$ & - atendimento $\left(\chi^{2}=74\right)$ & - tratamento $\left(\chi^{2}=69\right)$ & - cap $\left(\chi^{2}=63\right)$ \\
\hline
\end{tabular}

$\mathrm{Na}$ classe 1encontramos entre as principais formas reduzidas os seguintes: mãe, filh (filho, filha, filhinha, filhas), mor (mora, morais, moram, morar, morava, moreno, morou), pai ecas (casa, casada, casal, casas). Na classe 2 constam as variáveis: mês_janeiro $\left(\chi^{2}=190\right)$ e caderno_cidades $\left(\chi^{2}=97\right)$, quadr (quadra, quadras, quadro), residenci (residencia, residenciais, residencia), bloco (ou blocos), norte e comerci (comerciais, comercial, comerciantes, comercio). Na classe 3as variáveis foram: policia (policia, policiais, policiamento, policias), pres (presa, presas, preso, pressão), quadrilha (ou quadrilhas), acusad (acusadas, acusado) e delegacia_de policia.

Na classe 4observamos as presenças: apreens (apreensão, apreensões), coca (ou cocaína), merla, crack e aumente (aumenta, aumentado, aumentam, aumentando, aumentaram). $\mathrm{Na}$ classe 5observamos a presença das formas: explor (explora, exploração, explorada, explorar), boate (ou boates), rodovia (ou rodovias), sexual (ou sexualmente), esmol (esmola, esmolas, esmoleu). Finalmente, na classe 6, observamos a presença das variáveis: caderno_brasil $\left(\chi^{2}=120\right)$ e mês_dezembro $\left(\chi^{2}=96\right)$. Ainda, constatamos entre as principais formas reduzidas os termos: saúde, (psiquiatra, psiquiatria, psiquiátrica, psiquiátricas, psiquiátrico), atendimento (ou atendimentos), cap (caps).

Após a identificação das formas reduzidas e a leitura das UCE, procedemos à identificação das ideias principais contidas em cada uma das classes. O conteúdo das ideias contidas em cada uma das classes é apresentado a seguir.

Classe 1 - Como o problema da violência associada ao uso de crack e a criminalidade afetam os laços familiares. A classe 1 apresenta diversas situações de violência, ressaltando aquelas no contexto doméstico, dentre as quais se destacam as brigas, discussões, ameaças, chantagens e roubos. Também aparecem as questões da dependência associada à fissura e a dependência da droga como causa da no passado. Aqui fica marcado um forte estigma sobre o usuário de droga, por meio da utilização de vocábulos como viciados, cracolândia, traficante, consumidores, pedinte e destruição, indicando um discurso repressivo e uma ausência de perspectivas preventivas.

Classe 3 - Ação policial: $O$ enfrentamento ao traficante e às quadrilhas. A classe 3 encerraações de apreensão e de combate ao narcotráfico realizada pela polícia. As reportagens relataram os óbitos e prisões resultantes da ação de repressão policial, e também mostram um cenário de guerra em que a polícia enfrenta quadrilhas fortemente armadas e organizadas. Na classe 3 nota-se um alto valor de qui-quadrado dos cadernos "Cidade" e "Opinião". Também podemos identificar a intensificação das ações de combate realizada pela polícia nos meses de abril, fevereiro, agosto e julho.

Classe 4 - Apreensões de droga. As drogas apreendidas que apareceram nessa classe em ordem crescente de quiquadrado foram: coca, merla, crack, ecstasy e haxixe. A palavra repressão também ocorreu diversas vezes, o que nos leva a pensar que essa classe possui uma representação da apreensão como fruto do combate às drogas. Está expresso nessa classe o aumento da apreensão, mais evidente no mês de outubro, com falas sobre a droga no "Caderno Ciência".

Classe 5 - Indigência e exploração sexual. A classe 5 traz narrações de exploração sexual e expõe relatos de jovens com histórias de abandono e violência nos quais muitas vezes as menores negam a idade e usam documentos falsos. Também há relato de estupros. Há relatos de mulheres jovens vítimas de abuso que muitas vezes abandonam suas atividades de trabalho e de estudo e passam por problemas com drogas. Ao se encontrarem nessa situação, demonstram irritação, ansiedade, perda de apetite, depressão frequente e passam a consumir mais bebida alcoólica. 
Classe 6 - Investimento no atendimento psiquiátrico. A classe 6 está relacionada ao tratamento do usuário de drogas e também aos investimentos do governo no atendimento e tratamento de dependentes. Nessa classe, fala-se de hospitais, do atendimento psiquiátrico e da criação de leitos. $\mathrm{O}$ tratamento ao usuário foi encontrado nos meses de maio,
A seguir faremos a leitura da figura 3 , que ilustra a AFC gerada pelo ALCESTE:

O conteúdo das classes 1 e 5 diz respeito à violência em espaços domésticos e na rua, com ou sem o envolvimento com o crack. Nota-se que esse grupo temático está presente abaixo do eixo $1(29 \%)$ e deslocado para a direita do eixo

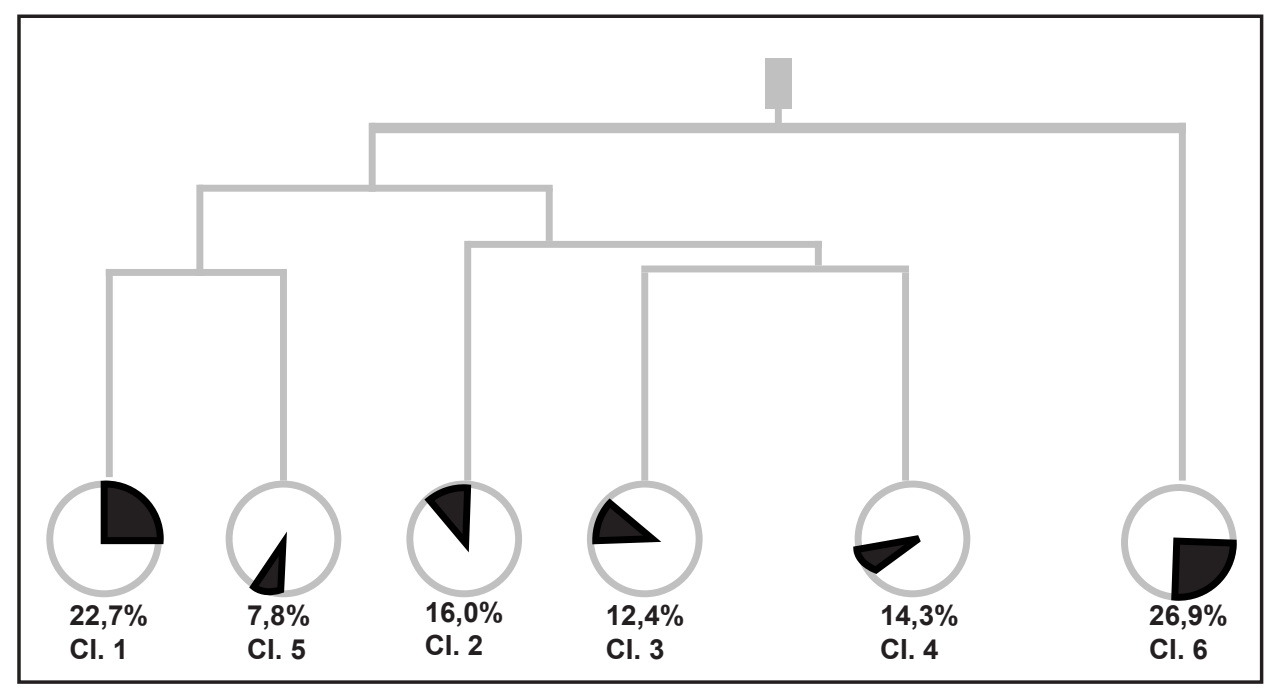

Figura 2. Classificação hierárquica descendente

setembro e, principalmente, no mês de dezembro. Entre os cadernos o destaque nessa classe é "Caderno Brasil".

Após a definição inicial do que cada classe representa em termos de sua contribuição para a produção de sentidos, procedemos à descrição da Figura 2, que ilustra a CHD gerada pelo ALCESTE.

A articulação da classe 1 com a classe 5 fundamenta um thema, que contém a antinomia de que por um lado a droga precisa ser combatida, porque ela é uma ameaça para as famílias. Por outro lado, existe a exposição da situação do usuário nas condições de vulnerabilidade social e miséria.

A articulação entre a classe 3 e a classe 4 fundamenta outro thema, que revela a oposição entre o fato de que as ações policiais estão preocupadas em proteger a vida, e por isso agem conforme prevê a política sobre drogas no seu aspecto da redução da oferta (apreendendo drogas), mas por outro lado, na classe 3 observamos o elevado índice de mortes resultantes dessas ações. Esse thema identificado na relação entre as classes 3 e 4 se opõe ao cenário criado pela classe 2 , no sentido de que por um lado existe um cenário de guerra às drogas, e por outro, de que os usuários circulam livremente, denegrindo a imagem da cidade e ameaçando os cidadãos de bem, indicando outro thema: eliminar a droga ou o usuário?

Por último, a classe 6 encerra uma nova antinomia ao se articular com os demais mundos lexicais encontrados pelo ALCESTE neste estudo. Por um lado, revela-se a existência de um cenário degradante com baixo nível de qualidade de vida, guerras, apreensões, vulnerabilidade e, do outro, indicado na classe 6 , existe a oferta de atendimento na qual o governo apresenta a solução única para o problema pela via da internação psiquiátrica.
2 (23\%). Podemos identificar, nesse quadrante, a antinomia que encerra o usuário enquanto sujeito em contexto de vulnerabilidade que carece de proteção e, por outro lado, temos a noção de que a droga atrai a violência, também observada na CHD (vide Figura 2).

A ideia apontada pelas classes 3 e 4 descreve as ações violentas da polícia no combate e repressão e os resultados alcançados por elas: mortes, prisões e a apreensão de drogas. Acima do eixo 1, constam as ideias de apreensão (redução da oferta) e tratamento. Nota-se que os mundos lexicais das classes 3 e 4 estão localizados em oposição aos themata das classes 1 e 5, que estão para baixo do eixo 1 .

A partir disso, foi possível criar a primeira representação social que é a noção da "droga como o flagelo da sociedade", construída com base no cenário de violência, morte e destruição que a droga deixa em seu lastro. Ela surge a partir da combinação da classe 1 com a classe 5 , que dizem respeito à violência em contextos familiares e na rua, com ou sem a presença do crack. Segundo a CHD, essas classes, quando combinadas com as classes 3 e 4 , nas quais foram encontradas as ações de combate e repressão da polícia que provocam mortes, prisões e apreensão de droga, configuram a representação da droga como o flagelo da sociedade encerrando os themata violência familiar (combate)/usuários indigentes (proteção), morte/vida, repressão/cuidado com o usuário. A AFC nos oferece os seguintes themata, que se opõem pelo eixo 2: violência familiar (combate)/usuários indigentes (proteção) de um lado e, por outro, o cenário de consumo/apreensões, ações de segurança (com morte)/ ações de saúde (protegendo a vida?), reforçando os achados da CHD. 
A segunda representação foi elaborada a partir da confluência das classes 3 e 4 em combinação com a classe 2 . Nessa representação, a mídia reproduz o medo, fazendo com que se crie certo estado de pânico na sociedade em relação à onipresença do "grande mal". Nela, podemos identificar o cenário de medo e ameaça que a droga carreia e o interesse em representar o usuário do crack enquanto delinquente que ameaça a ordem social. Ele não apenas ameaça, mas anda livre nas ruas da cidade enquanto que esforços monumentais são realizados pela polícia, que paga com o preço da vida, para salvar a sociedade do mal.

A criação da terceira representação social é marcada pela oposição do eixo 2 , que coloca os themata da necessidade de tratamento aos usuários e, portanto, da ênfase na abordagem ao "problema do crack como uma questão de saúde", em oposição com às outras classes - exceto feita à classe 4, em virtude da menção à apreensão das drogas nessa classe, evidenciando o crack como maior problema (a merla, a coca, o haxixe e o ecstasy aparecendo com menor frequência), e do porque essa ação se consubstancia enquanto redução de oferta, complementar à ideia da classe 6 , mais relacionada ao tratamento do usuário de drogas e também aos investimentos do governo no atendimento aos dependentes. Na classe6 fala-se em hospitais, na criação de leitos, no atendimento e na postura psiquiátrica. No entanto, ela está mais afastada do eixo 2, enquanto que as drogas e as ações de apreensão (classe 4) estão mais próximas dele. Isso significa que o jornal apresenta um enfoque maior na apreensão das drogas, enquanto que as matérias que falam do atendimento ficam num segundo plano, como complemento do que é veiculado.

\section{Discussão}

A primeira representação social sugere que a violência familiar é um fator de risco associado à presença da droga na vida dos filhos, gerando a cena do tráfico e do consumo (classe 2). Expressando de outra maneira, a sociedade considera que a organização da estrutura familiar, o modelo apresentado pelos pais, o intercâmbio afetivo e o relacionamento interpessoal nas relações familiares contribuem marcadamente para a opção do jovem pelo uso de drogas (Martins, Espírito Santo, \& Percílio, 2000).

Notamos que a mídia expõe a presença de um ciclo vicioso, em que as intervenções policiais atuam de forma a manter ou aumentar a violência, intensificando os problemas e gerando mais violência. No entanto, com a análise ALCESTE, percebemos que nem sempre a droga está presente nas situações de violência descritas pelo Correio, o que pode se observar pelas palavras contidas na classe 5 , o que nos leva a refletir se a droga é necessariamente o grande mal da sociedade. No entanto, quando se trata de abordar o tema da droga, apresenta-se nitidamente o cenário de violência que parece justificar a postura da polícia no combate à droga, ao contrário do que legalmente se prevê pela nova lei sobre drogas (Veríssimo, 2010), assim, a droga como flagelo deve ser expurgada do ambiente saudável de convivência social (Noto, Baptista, Faria, Nappo, Galduróz, \& Carlini, 2003; Romanini \& Roso, 2012)
Na segunda representação social encontramos os ingredientes que a mídia utiliza para produzir o pânico moral, provocando um alarde no leitor que não consegue compreender a situação (Altheide \& Michalowski, 1999; Reinarman \& Levine, 1988/1997). Esse medo cria um distanciamento da droga e de seus usuários que acabam marginalizados (Romanini \& Roso, 2012). Assim, a mídia cria o que se chama de pacotes de discurso e de realidade nos quais o indivíduo não interage com os fatos reais, mas apenas toma ciência pela mediação da mídia, que por vezes é distorcida (Cierco, 2003).

Njainee e Minayo (2004) apontam que a dessensibilização (indiferença à violência dirigida a terceiros e omissão em relação à vítima) e a intensificação do medo de serem vítimas da violência na vida real são algumas das consequências da exposição da violência na mídia. A classe 2 ilustra essa noção ao destacar a falta de controle efetivo sobre a venda e o consumo da droga no Brasil (Correio Braziliense, mês de junho, Caderno Cidades). Nesse sentido, o jornal descreve as cenas de consumo e tráfico no centro da cidade, nos bairros residenciais, nos parques e com isso intensifica a sensação de insegurança, fomentando a repressão ao usuário (Romanini \& Roso, 2012).

A criação da terceira representação social é marcada pela oposição estabelecida pelo eixo 2 , que nos mostra o thema da necessidade de tratamento aos usuários e em oposição ao cenário da degradação dos usuários e do envolvimento violento da polícia. Portanto, da ênfase na abordagem ao problema do crack como uma questão de saúde, em oposição às outras classes, exceto a classe 4 , em virtude desta apresentar a droga como maior problema e de efetivar a ação de redução de oferta, complementar à ideia do tratamento que está presente na classe 6 .

A classe 6 , que indica o atendimento ao usuário, representa $26,4 \%$ do corpus. Por outro lado, $73,6 \%$ do conteúdo das matérias do Correio são relativas ao contexto de violência em torno da droga. Assim, apesar da classe 6 possuir o maior volume de reportagens em relação às demais, ela se encontra em oposição às outras classes, de forma que sua expressividade percentual perde força em comparação ao eixo semântico das demais classes.

Dessa forma, apesar de identificarmos uma discussão orientada para a área da saúde, não há a presença de falas que sugiram a reintegração do usuário à sociedade. Isso contribui para a manutenção do estigma e da marginalização do usuário de drogas. Embora, na contramão, a legislação atual sobre drogas prevê uma forma menos excludente de lidar com o usuário (Veríssimo, 2010).

Cabe também outra crítica à maneira como as reportagens abordam a questão do tratamento, pois estas vêm sempre ligadas a uma ação a posteriori, isto é, que tratam apenas das opções de tratamento para o usuário quando ele já se apresenta dependente da droga, destacando apenas sua vulnerabilidade. Essa perspectiva se efetua em detrimento da divulgação de programas de prevenção e de informações que poderiam favorecer a proteção de sujeitos em situação de risco ou vulnerabilidade, à promoção da saúde de todos, que é um direito previsto constitucionalmente.

A polêmica circula em torno da aceitação de um grupo de indivíduos caracterizados como usuários que estão presentes 
em todos os contextos sociais, e não apenas em grupos marginalizados. Dessa forma, a prevenção universal, voltada para todos, fica prejudicada, já que o foco recai sobre os "pobres (leia-se miseráveis) dependentes do crack". Assim, se por um lado indicam soluções no âmbito das políticas públicas para os casos mais crônicos, por outro, omitem as iniciativas da prevenção primária.

As representações sociais encontradas neste estudo se coadunam com o imaginário social que preconiza uma abordagem estigmatizante e repressiva da droga e que possui um discurso com alto nível de tendenciosidade representando o crack como abismático, flagelo e horror. Outro fato é a desproporção de matérias jornalísticas com foco sobre as drogas ilícitas, o que é refletido diretamente na percepção da população, distorcendo as crenças relativas ao uso de substâncias psicoativas no país (Noto et al., 2003).

Por sua vez, as representações da droga como algo que está invadindo os espaços urbanos em vertiginoso crescimento, podem provocar insegurança no leitor que passa a se tornar direta ou indiretamente atingido. Se por um lado isso mobiliza a sociedade e a torna co-responsável pelo problema, motivando-a na busca de soluções, por outro lado, provoca o que se convencionou chamar de pânico moral, além de gerar o preconceito e a discriminação do usuário (Reinarman \& Levine, 1988/1997).

A mídia é uma grande ferramenta que possui a capacidade de ampla divulgação, sendo assim uma modeladora da cultura, com o papel de difusora de informações. Por isso, ela deveria ser usada de forma a contribuir para o acesso democrático às informações, melhorando sua capacidade de ação, ao contrário de estigmatizar e manter as conservas da sociedade (Romanini \& Roso, 2012).

Apesar de uma nova legislação sobre drogas ter entrado em vigor, este estudo aponta que a prática não acompanhou a mudança ocorrida na lei. Essa constatação se faz em virtude da identificação de vestígios do antigo tratamento dado ao fenômeno, no qual predomina a abordagem repressora e punitiva aos usuários (Veríssimo, 2010). É certo que o problema do crack precisa ser tratado com toda a seriedade que o tema merece, principalmente em casos que envolvem crianças e adolescentes que supostamente deveriam estar sob a proteção do Estado, da família e da sociedade e não abandonadas nas ruas à própria sorte. Nesse sentido, o presente estudo mostrou que a mídia tem cumprido seu papel de arauto, alardeando o dramático problema social e lançando holofotes sobre a questão (Reinarman \& Levine, 1988/1997).

Em suma, circula no imaginário coletivo e nas notícias, a certeza de que o crack tornou-se um problema endêmico que está fugindo do controle do Estado, invadindo as ruas de pequenas e grandes cidades e que ele tem sido relacionado ao aumento da violência urbana. Tais representações sociais incitam e ovacionam iniciativas populescas de repressão policial (Romanini \& Roso, 2012; Veríssimo, 2010) e resoluções simplórias e paliativas.

Outra certeza embutida nas representações é de que a internação do usuário é a solução para o problema do $c r a c k$, o que retroalimenta o imaginário social que conclama a internação compulsória como solução para o problema, ainda que estudos tenham apontado para uma ineficácia parcial dessa proposta de tratamento (Guimarães et al., 2008). Por fim, destacamos que se trata de uma situação complexa na qual a condição de dupla exclusão de jovens nas camadas pobres favorece ainda mais a disseminação da droga (Sudbrack, 2010). Trata-se, portanto, de um grave problema social que merece a atenção do Estado e da sociedade, no sentido de que sejam encontradas respostas eficazes que tragam soluções humanizadas para o problema.

A continuidade de estudos envolvendo o tema do crack no contexto da sociedade brasileira é importante e necessário para que sejam apontadas as contradições de discurso e de posição em relação ao problema, que tendem a ofuscar as soluções mais eficazes, a reforçar a manutenção do mal-estar da sociedade e a promover a exclusão social de usuários de droga.

\section{Referências}

Altheide, D. L., \& Michalowski, R. S. (1999). Fear in the news: A discourse of control. The Sociological Quarterly, 38, 646-686.

Altheide, D. L. (2000). Tracking discourse and qualitative document analysis. Poetics, 27, 287-299.

Bastos F. I., \& Bertoni, N. (2013). Estimativa do número de usuários de crack elou similares nas Capitais do País. Retrieved from http://portal.fiocruz.br/pt-br/content/maior-pesquisasobre-crack-j\%C3\%A1-feita-no-mundo-mostra-o-perfil-doconsumo-no-brasil

Brasil. Gabinete de Segurança Institucional. Conselho Nacional Antidrogas. (2005). Resolução $n^{\circ} 3 / G S I P R / C H / C O N A D$, de 27 de outubro de 2005. Aprova a Política Nacional Sobre Drogas. Recuperado em 15 março, 2010, do Observatório Brasileiro de Informações sobre Drogas. Retrieved from http:// www.obid.senad.gov.br/portais/OBID/biblioteca/documentos/ Legislacao/326979.pdf.

Brasil. (2006). Lei $n^{\circ} 11.343$, de 23 de agosto de 2006. Institui o Sistema Nacional de Políticas Públicas sobre Drogas - Sisnad. Retrieved from http://www.planalto.gov.br/ccivil_03/_ Ato2004-2006/2006/Lei/L11343.htm.

Brasil (2010). Decreto $n^{\circ} 7.179$, de 20 de maio de 2010. Institui o Plano Integrado de Enfrentamento ao Crack e outras Drogas, cria o seu Comitê Gestor, e dá outras providências. Retrieved from http://www.planalto.gov.br/ccivil_03/_Ato20072010/2010/Decreto/D7179.htm

Centro Brasileiro de Informações sobre Drogas Psicotrópicas. (2012). VI Levantamento Nacional Sobre o Consumo de Drogas Psicotrópicas Entre Estudantes do Ensino Fundamental e Médio da Rede Pública e Privada de Ensino nas 27 Capitais Brasileiras e Distrito Federal, 2010. São Paulo/Brasília: CEBRID/UNIFESP/SENAD.

Camargo, B. V., \& Barbará, A. (2004). A difusão científica da mídia impressa. Psico, 35(2), 160-176.

Carvalho, H. B., \& Seibel, S. D. (2009). Crack cocaine use and its relationship with violence and HIV. Clinics, 64(9), 857-866.

Chagas, A. T., \& Seeger, F. D. (2013). Crack na Mídia Impressa: Um estudo sobre a produção de sentido no discurso jornalístico sobre o crack. Barbarói, 38, 145-177.

Cierco, G. B. R. (2003). Um retrato da droga na imprensa português (Unpublished doctoral dissertation). Universidade do Porto, Portugal. 
Cunha, P. J., Nicastri, S., Gomes L. P., Moino, R. M., \& Peluso, M. A. (2004). Alterações neuropsicológicas em dependentes de cocaína/crack internados: dados preliminares. Revista Brasileira de Psiquiatria, 26(2), 103-106.

Duailibi, L. B., Ribeiro, M., \& Laranjeira, R. (2008). Perfil dos usuários de cocaína e crack no Brasil. Cadernos de Saúde Pública, 24(4), 545-557.

Guimarães, C. F., Santos, D. V. V., Freitas, R. C., \& Araújo, R. B. (2008). Perfil do usuário de crack e fatores relacionados à criminalidade em unidade de internação para desintoxicação no Hospital Psiquiátrico São Pedro de Porto Alegre (RS). Revista de Psiquiatria do Rio Grande do Sul, 30(2), 101-108.

Jodelet, D. (1986). La representación social: fenómeno, concepto y teoría. In S. Moscovici (Ed.), Pensamiento y Vida Social (pp. 469-494). Buenos Aires: Paidós.

Jovchelovitch, S. (1995). Vivendo a vida com os outros: intersubjetividade, espaço público e representações sociais. In P. E. Guareschi \& S. Jovchelovitch (Eds.), Textos em Representações Sociais (pp. 61-85). Petrópolis: Vozes.

Lima, L. C. (2008). A Articulação "Themata-Fundos Tópicos": por uma Análise Pragmática da Linguagem. Psicologia: Teoria e Pesquisa, 24(2), 243-246.

Mançano, A., Marchiori, E., Zanetti, G., Escuissato, D. L., Duarte, B. C., \& Apolinário, L. de A. (2008). Complicações pulmonares após uso de crack: achados na tomografia computadorizada de alta resolução do tórax. Jornal Brasileiro de Pneumologia, 34(5), 323-327.

Martins, F., Espírito Santo, L., \& Percílio, D. (2000). A representação social da droga em Brasilia/BR. Retrieved from http://www. redalyc.org/pdf/946/94626109.pdf

Moscovici, S. (1978). A Representação Social da Psicanálise. Rio de Janeiro: Zahar.

Moscovici, S. (Ed.) (1984). Psychologie sociale. Paris: PUF.

Moscovici, S., \& Vignaux, G. (1994). Le concept de Themata. In C. Guimelli (Ed.), Structures et Transformations des Représentations Sociales (pp. 25-72). Neuchâtel: Delachauxet Niestlé.

Moscovici, S. (2003). Representações sociais: Investigações em Psicologia Social. Petrópolis: Vozes.

Nascimento, A. R. A., \& Menandro, P. R. M. (2006). Análise lexical e análise de conteúdo: uma proposta de utilização conjugada. Estudos e Pesquisas em Psicologia, 6(2), 72-88.

Njaine, K., \& Minayo, M. C. S. (2004). A violência na mídia como tema da área da saúde pública: revisão da literatura. Ciência e Saúde Coletiva, 9(1), 201-211.
Noto, A. R., Baptista, M. C., Faria, S. T., Nappo, S. A., Galduróz, J. C. F., \& Carlini, E. A. (2003). Drogas e saúde na imprensa brasileira: uma análise de artigos publicados em jornais e revistas. Cadernos de Saúde Pública, 19(1), 69-79.

Oliveira, L. G. de. \& Nappo, S. A. (2008). Caracterização da cultura de crack na cidade de São Paulo: padrão de uso controlado. Revista de Saúde Pública, 42(4), 664-671.

Reinarman, C., \& Levine, H. G. (1997). The Crack attack. Politics and Media in the crack scare. In C. Reinarman \& H. G. Levine (Eds.), Crack in America: Demon Drugs and Social Justice (pp. 18-52). Berkeley: University of California Press. (Trabalho original publicado em 1988)

Romanini, M., \& Roso, A. (2012). Mídia e Crack promovendo saúde ou reforçando relações de dominação. Psicologia: Ciência e Profissão, 32(1), 82-97.

Rouquette, M. L. (1988). Les communications de masse. In S. Moscovici (Ed.), Psychologie Sociale (2 ed., pp. 495-512). Paris: Presses Universitaires de France. (Trabalho original publicado em 1984)

Santoucy, L., Conceição, M. I. G. C., \& Sudbrack, M. F. O. (2010). A Compreensão dos Operadores de Direito do Distrito Federal sobre o Usuário de Drogas na Vigência da Nova Lei. Psicologia: Reflexão e Crítica, 26(1), 37-46.

Silva, C. R. da., Kolling, N. de. M., Carvalho, J. C. N., Cunha, S. M. da., \& Kristensen, C. H. (2009). Comorbidade psiquiátrica em dependentes de cocaína/crack e alcoolistas: um estudo exploratório. Aletheia, 30, 101-112.

Sudbrack, M. F. O. (2010). Acolhendo adolescentes em situação de risco pelo envolvimento com drogas no contexto de vulnerabilidade social. In M. F. O. Sudbrack, M. I. G. Conceição, \& L. F. Costa (Eds.), Curso de Prevenção do Uso de Drogas para Educadores de Escolas Públicas (4⿳a ed., pp. 181-183). Brasília: SENAD- Secretaria Nacional de Políticas sobre Drogas.

Thompson, J. B. (2007). Ideologia e Cultura Moderna - teoria social crítica na era dos meios de comunicação de massa. Petrópolis, RJ: Vozes.

Valsiner, J. (2012). The Oxford Handbook of Culture and Psychology. New York: Oxford University Press.

Veríssimo, M. (2010). A nova lei de drogas e seus dilemas. Apontamentos para o estudo das formas de desigualdade presentes nos interstícios do ordenamento jurídico-penal brasileiro. Civitas - Revista de Ciências Sociais, 10(2), 330344.

Zeni, T. C., \& Araújo, R. B. (2009). O relaxamento respiratório no manejo do craving e dos sintomas de ansiedade em dependentes de crack. Revista de Psiquiatria do Rio Grande do Sul, 31(2), 116-119. 